\title{
The human area postrema: clear-cut silhouette and variations shown in vivo
}

\author{
Pierluigi Longatti, MD, ${ }^{1}$ Andrea Porzionato, MD, PhD, ${ }^{2}$ Luca Basaldella, MD, ${ }^{1}$ \\ Alessandro Fiorindi, MD, PhD, ${ }^{1}$ Pietro De Caro, Eng, ${ }^{3}$ and Alberto Feletti, MD, PhD ${ }^{1}$ \\ 1Department of Neurosurgery, Treviso Hospital, University of Padova; and Departments of ${ }^{2}$ Human Anatomy and ${ }^{3}$ Information \\ Engineering, University of Padova, Italy
}

OBJECT The human area postrema (AP) is a circumventricular organ that has only been described in cadaveric specimens and animals. Because of its position in the calamus scriptorius and the absence of surface markers on the floor of the fourth ventricle, the AP cannot be clearly localized during surgical procedures.

METHODS The authors intravenously administered $500 \mathrm{mg}$ fluorescein sodium to 25 patients during neuroendoscopic procedures; in 12 of these patients they explored the fourth ventricle. A flexible endoscope equipped with dual observation modes for both white light and fluorescence was used. The intraoperative fluorescent images were reviewed and compared with anatomical specimens and 3D reconstructions.

RESULTS Because the blood-brain barrier does not cover the AP, it was visualized in all cases after fluorescein sodium injection. The AP is seen as 2 coupled leaves on the floor of the fourth ventricle, diverging from the canalis centralis medullaris upward. Although the leaves normally appear short and thick, there can be different morphological patterns. Exploration using the endoscope's fluorescent mode allowed precise localization of the AP in all cases.

CONCLUSIONS Fluorescence-enhanced inspection of the fourth ventricle accurately identifies the position of the AP, which is an important landmark during surgical procedures on the brainstem. A better understanding of the AP can also be valuable for neurologists, considering its functional role in the regulation of homeostasis, emesis, and cardiovascular and electrolyte balance. Despite the limited number of cases in this report, evidence indicates that the normal anatomical appearance of the AP is that of 2 short and thick leaves that are joined at the midline. However, there can be great variability in terms of the structure's shape and size.

http://thejns.org/doi/abs/10.3171/2014.11.JNS14482

KEY WORDS anatomy; area postrema; circumventricular organ; fluorescence; human; in vivo; endoscopy; fourth ventricle; diagnostic and operative techniques

$\mathrm{T}$ HE Swedish anatomist Magnus Gustav Retzius (1842-1919) first defined the human area postrema (AP) in 1896 as a median spongy structure strategically positioned at the level of the Magendie foramen (Fig. 1). ${ }^{25}$ The AP is one of the main circumventricular organs, a group of ventricular anatomical structures that perform reciprocal receptorial functions between the central nervous system and the organism..$^{1,3}$ The structural body of the AP consists of a loose neuroglial network crossed by numerous blood vessels that give rise to a widely anastomosed capillary network characterized by the presence of loops, spirals, and sinusoid conformations with no blood-brain barrier (BBB). ${ }^{3}$

The functions of the AP have been mainly demon- strated in animals, and they include fluid and electrolyte balance, cardiovascular regulation, energetic homeostasis preservation, and triggering of emesis. ${ }^{4,5,17-19,24,28-30,32}$

The anatomical and morphological description of the human AP has always been based on the microscopic observation of brainstem sections. ${ }^{3,20,24,29,30-32}$ Microsurgery provides far fewer details than cadaver observations. At surgical inspection, with very few exceptions, all of the structures seem flattened in the intense whiteness of the ependymal surface. As the location of important structures can be only roughly visualized rather than precisely identified, neurosurgeons mainly rely on electrophysiological mapping to identify them.

Recently, we have coupled the use of fluorescein angi- 


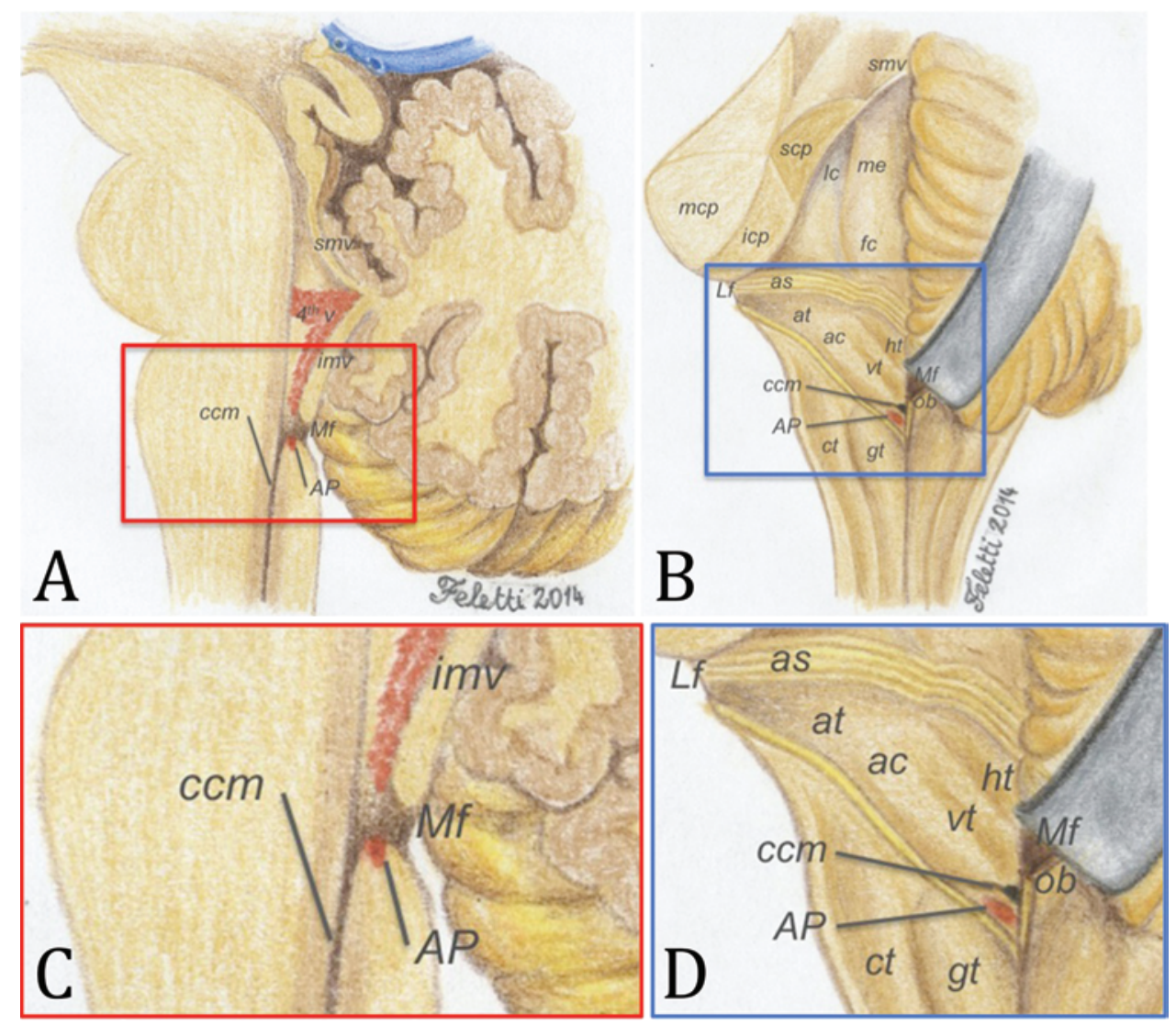

FIG. 1. Illustrations showing the position of the AP in relation to the fourth ventricle structures. A: Sagittal view. Contrary to common belief, the AP is positioned dorsally to the canalis centralis medullaris, being the very last structure of the rhomboid fossa. B: View of the posterior fossa structures from a dorsal perspective. The retractor lifts the cerebellar tonsil and unveils the Magendie foramen, as seen during a microsurgical approach (right). From this perspective, both the AP and the canalis centralis medullaris are not visible, because of the presence of the obex membrane. The cerebellum and the obex membrane have been totally removed to show the floor of the fourth ventricle and the calamus scriptorius (left). C and D: Enlarged views of $A$ and $B$, respectively. ac = ala cinerea; as = acoustic striae; at = acoustic tubercle; $\mathrm{ccm}=$ canalis centralis medullaris; $\mathrm{ct}=$ cuneate tubercle; $\mathrm{fc}=$ facial colliculi; gt = gracile tubercle; $\mathrm{ht}=$ hypoglossal trigone; icp = inferior cerebellar peduncle; imv = inferior medullary velum; lc = locus caeruleus; $\mathrm{Lf}=$ Luschka foramen; $\mathrm{mcp}=$ middle cerebellar peduncle; $\mathrm{me}=$ median eminence; $\mathrm{Mf}=$ Magendie foramen; ob = obex; $\mathrm{scp}=$ superior cerebellar peduncle; $\mathrm{smv}=$ superior medullary velum; $\mathrm{vt}=$ vagal trigone; 4thv = fourth ventricle. Copyright Alberto Feletti. Published with permission. Figure is available in color online only.

ography and the ventricular endoscopic navigation technique with the purpose of identifying the position of blood vessels at the level of the median eminence to preserve them during endoscopic third ventriculostomy (ETV) procedures. ${ }^{10}$ Transaqueductal navigation of the fourth ventricle with a flexible scope for diagnostic and treatment purposes gave us the opportunity to observe the fluorescent AP after intravenous injection of fluorescein sodium.,12 An anatomical paradigm of a normal AP was created by obtaining 3D reconstructions using slices from cadaveric brainstems. Three-dimensional reconstructions allow a comprehensive view of the AP, showing its relationship to other structures of the fourth ventricle and indirectly marking its boundaries.

This study builds on our experience with fluorescein visualization of the AP and provides a comparison with images of anatomical sections and $3 \mathrm{D}$ reconstructions, to confirm the ability of fluorescence to precisely outline the portion of the AP that projects into the fourth ventricle.

\section{Methods}

We reviewed all 25 cases of fluorescein-assisted neuroendoscopic procedures that have been performed at our institution since 2011. Only the 12 cases of transaqueductal fourth ventricle exploration were included in this study. There were 6 cases of obstructive hydrocephalus due to aqueductal functional substenosis; 2 cases of posthemorrhagic hydrocephalus; 1 case each of colloid cyst, third ventricle cyst, and tetraventricular hemorrhage; and 1 biopsy for a suspect hystiocytosis with cerebral localizations (Table 1).

We used flexible scopes $(2.5-\mathrm{mm}$ or $3.5-\mathrm{mm}$ diameter, Karl Storz) for all surgeries. The scope was set with 2 lenses, which could be switched to obtain inspection with either white light (for standard visualization) or blue light (for fluorescence visualization, D-light AF system; Karl Storz Endoscopy). A 14-F peel-away sheath was inserted, as usual, into the right frontal horn through a right precoronal bur hole positioned $2 \mathrm{~cm}$ from the midline. Systolic blood pressure was maintained at $120 \mathrm{~mm} \mathrm{Hg}$. The flexible scope was 
TABLE 1. Case series

\begin{tabular}{|c|c|c|c|c|c|c|c|}
\hline Patient & $\begin{array}{l}\text { Age (yrs) } \\
\text { Sex }\end{array}$ & Pathology & Surgery & $\begin{array}{l}\text { Magendie } \\
\text { Foramen }\end{array}$ & AP & $\begin{array}{l}\text { Joined } \\
\text { Leaves }\end{array}$ & $\begin{array}{l}\text { Normal 4th } \\
\text { Ventricle }\end{array}$ \\
\hline 1 & $66, M$ & $\begin{array}{l}\text { Post-SAH hydrocephalus, malfunc- } \\
\text { tioning VP shunt }\end{array}$ & Exploration & Small & Short \& thick & No & No \\
\hline 2 & $72, \mathrm{M}$ & Hematocephalus totalis & Aspiration & Medium & Short \& thick & Yes & Yes \\
\hline 3 & $40, M$ & $\begin{array}{l}\text { Hydrocephalus, pineal \& infun- } \\
\text { dibular localization of Erdheim- } \\
\text { Chester histiocytosis }\end{array}$ & Biopsy & Large & Long \& thin & Yes & No \\
\hline 4 & $79, \mathrm{~F}$ & Obstructive hydrocephalus & ETV & Small & Short \& thick & No & No \\
\hline 5 & $58, \mathrm{M}$ & Colloid cyst & Aspiration & Medium & Short \& thick & Yes & Yes \\
\hline 6 & $62, \mathrm{M}$ & Obstructive hydrocephalus & ETV & Medium & Short \& thick & Yes & No \\
\hline 7 & $78, \mathrm{M}$ & Obstructive hydrocephalus & ETV & Large & Long, thin, dashed & Yes & No \\
\hline 8 & $19, \mathrm{M}$ & Hydrocephalus, pineal cyst & Biopsy, aspiration & Large & Short \& thin & Yes & No \\
\hline 9 & $63, \mathrm{M}$ & Obstructive hydrocephalus & ETV & Small & Short \& thin & Yes & No \\
\hline 10 & $64, \mathrm{~F}$ & Obstructive hydrocephalus & ETV & Large & Long \& thin & Yes & No \\
\hline 11 & $0, F$ & $\begin{array}{l}\text { Posthemorrhagic hydrocephalus, } \\
\text { isolated 4th ventricle }\end{array}$ & $\begin{array}{l}\text { Endoscope-assisted catheter } \\
\text { positioning in the 4th ventricle }\end{array}$ & Small & Long \& thin & Yes & No \\
\hline 12 & $56, M$ & Obstructive hydrocephalus & ETV & Large & Long, thin, dashed & No & No \\
\hline
\end{tabular}

$\mathrm{SAH}=$ subarachnoid hemorrhage; $\mathrm{VP}=$ ventriculoperitoneal.

then introduced using a free-hand technique. Initially, the lateral, third, and fourth ventricles were inspected with the white light. After performing this initial inspection in the standard white light mode, we kept the endoscope outside the ventricle. A solution of $500 \mathrm{mg}$ fluorescein sodium was then administered intravenously by the anesthesiologist, following the protocol used by ophthalmologists for retinal angiography. The protocol was submitted to the local ethics committee, and each patient provided signed informed consent. The ventricles were then neuroendoscopically inspected again using the fluorescence mode. Every time an adjustment of the position of the endoscope was required, the white light mode was set to avoid any damage to the ventricular walls. All procedures were entirely recorded and reviewed to define the precise pattern of fluorescence of any functionally active area, focusing in particular on the AP for morphological assessment.

The patients' MR images were reviewed to establish the extent of dilation of the fourth ventricle and Magendie foramen and their potential relationship with AP morphology. In those patients affected by either a cyst of the third ventricle or intraventricular hemorrhage, we assumed that the anatomy of the fourth ventricle was normal. In such cases, neuroendoscopic exploration of the fourth ventricle was required to aspirate potential colloid fragments or blood clots, to free the outlets of the ventricle itself.

From an anatomical point of view, the AP cannot easily be identified by the naked eye in postmortem specimens because its boundaries are not always well defined on direct visualization of the floor of the fourth ventricle. Thus, to compare the endoscopic appearance of the AP with its basic anatomical characteristics, we developed a $3 \mathrm{D}$ reconstruction of the AP created from transverse serial sections of a medulla oblongata obtained at autopsy. The brainstem was sampled within 36 hours of death from a patient without any brain-related pathology. It was fixed in $10 \%$ formalin for 10 days and was then transversally cut in blocks, which were embedded in paraffin. The block containing the AP was completely sectioned into serial 6- $\mu \mathrm{m}-$ thick sections that were stained with Nissl. The 3D aspect of the AP was also reconstructed using the Visualization Toolkit, a software system for 3D computer graphics, image processing, and visualization. In each section used for reconstruction, the boundaries of the AP were delineated together with the limits of the floor of the fourth ventricle. The boundaries of the AP were defined according to those of Paxinos and Huang ${ }^{21}$ and Tork ${ }^{31}$ et al., as well as from previous studies of our research group. ${ }^{15,18,22,23}$ In particular, the delineation of the AP is quite easy on Nisslstained sections because of its particular structural characteristics. It consists of a loose network of neuroglia with high-density vascularization and a few small neurons, which is clearly defined from the near nervous tissue. The limits of the ventricular surface of the AP are also easily identifiable because of slight bulging of the structure and peculiar morphology of its ependymal cells, the so-called tanycytes, extending deep into the AP.

\section{Results}

We identified the fluorescent AP in all cases. The AP appeared as 2 symmetrical leaves attached to the inferior angle of the floor of the fourth ventricle and caudally converging to the median line. After entering the fourth ventricle and when approaching the Magendie foramen in 5 cases, 2 symmetrical ocher areas were noted just lateral to the obex. The shape and the position of these areas explored using the white light mode might have led the surgeon to identify the areas as the AP. However, after activation of the fluorescent mode, the AP was clearly visible more dorsally, with its junction being immediately caudal to the canalis centralis medullaris. Fluorescence usually revealed the AP about 20 seconds after intravenous injection and lasted at least 1 minute. 
We observed some variations in both the shape and the size of the AP. In 2 cases of a colloid cyst of the third ventricle and intraventricular hemorrhage, the anatomy of the fourth ventricle was considered normal. In these cases, the pathology either did not affect the fourth ventricle (colloid cyst of the third ventricle) or it represented a temporary and acute dilation of a normal fourth ventricle (intraventricular hemorrhage). We noticed that in both cases the AP appeared as 2 short and thick leaves that were joined at the midline (Fig. 2, Video 1).

VIDEO 1. The fourth ventricle is inspected through transaqueductal navigation. The AP normally appears as 2 short and thick leaves in the calamus scriptorius. Copyright Alberto Feletti. Published with permission. Click here to view with Media Player. Click here to view with Quicktime.

Conversely, long-standing hydrocephalus affecting other patients was thought to have chronically distorted the ventricles, resulting in a variation of the shape of the AP. In all but one of these cases the 2 leaves were either long and thin or split at the midline. In general, we distinguished at least 4 different anatomical patterns in terms of shape, based on the profile of the 2 symmetrical leaves, which can appear short and thick $(n=5)$; short and thin $(n=2)$; long, thin, and continuous ( $\mathrm{n}=3$ ); or long, thin, and dashed (2). Moreover, the 2 leaves can be either joined at the midline $(n=9)$ or separated $(n=3)$ (Fig. 3, Video 2).

VIDEO 2. Anatomical variations of the AP. Copyright Alberto Feletti.

Published with permission. Click here to view with Media Player.

Click here to view with Quicktime.

Microscopic study of the AP anatomy showed that in the craniocaudal progression the right and left parts of the AP approach each other and join together at their most caudal extensions (Fig. 4A-D). This anatomical alignment gives rise to the 3D appearance shown in Fig. $4 \mathrm{E}$ and F, which confirms that the AP appears as 2 leaves caudally moving toward each other at their stalks. The 3D reconstruction was consistent with the normal endoscopic pattern of the AP as seen with fluorescence.

\section{Discussion}

Indications for exploring the fourth ventricle during a neuroendoscopic approach have been expanded during the last few years, requiring not only an accurate knowledge of the fourth ventricle anatomy, but also the possibility of identifying clear landmarks for navigation., ${ }^{9,11,13,14}$ The AP is a V-shaped structure on the floor of the fourth ventricle diverging from its apex at the obex in a rostral direction, always overlying the nucleus of the solitary tract.,25 Caudally, the AP can be observed bulging out from the rhomboid fossa 1-2 mm caudal to the opening of the central canal. As the fourth ventricle opens out, the bilateral prominences of the AP move dorsally and laterally in relation to the floor of the ventricle..$^{29}$ The AP is a circumventricular organ with no BBB, whose neurons are directly exposed to substances in the blood and tissue fluids. The circumventricular organs can be distinguished into 2 main groups: the neurosecretory structures, including the median eminence, the neurohypophysis, the pineal gland, and the sensory structures, including the subfornical organ, the organum vasculosum of the lamina terminalis, and the AP. The subcommissural organ is generally considered a specific circumventricular organ and is not included in the 2 groups mentioned above. ${ }^{5,16}$ The main function of the AP was unknown until half a century ago, when Borison and Wang showed its role in emesis. ${ }^{2}$ The roles played by the AP in cardiovascular regulation, fluid balance, osmoregulation, and immunomodulation are more recent scientific findings. $4,5,17,23,24,28,30,34$

Duvernoy and Risold published macroscopic images of
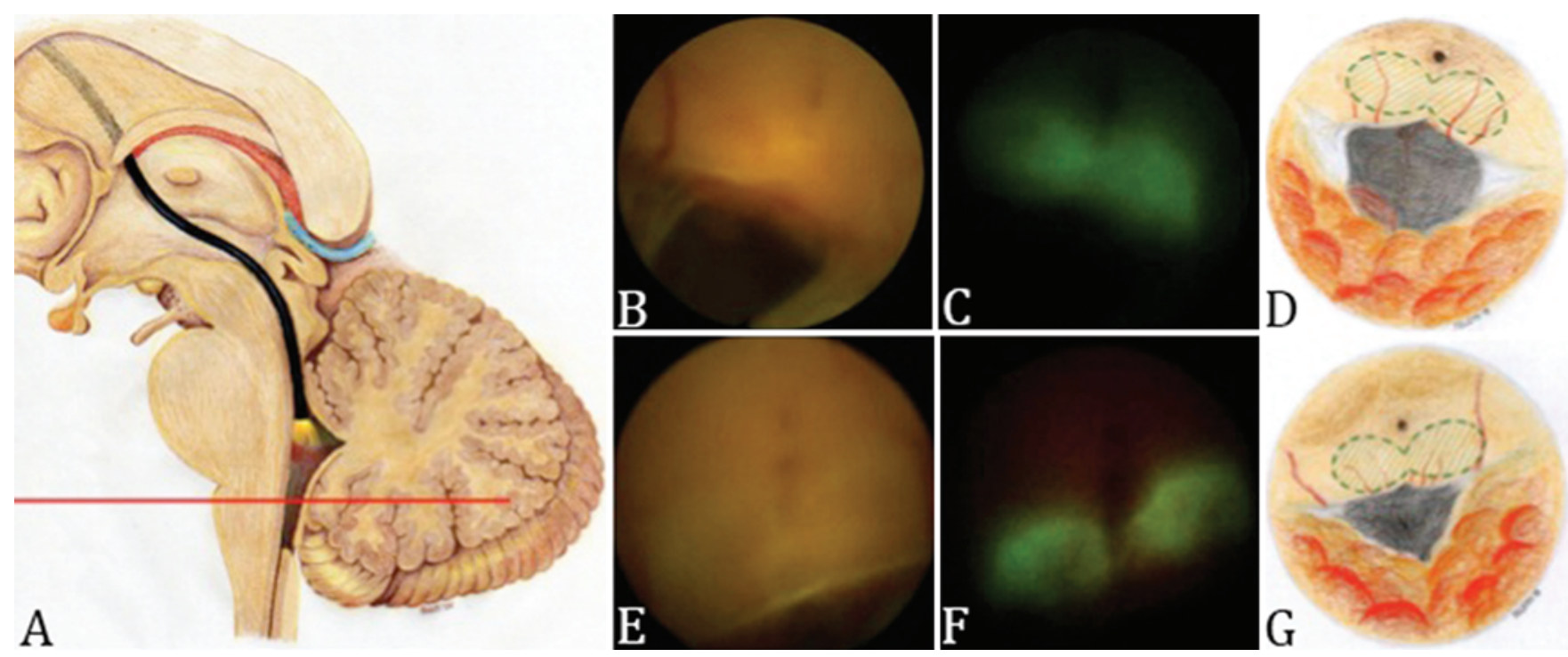

FIG. 2. Endoscopic visualization of the calamus scriptorius in a normal fourth ventricle. Artist's drawing showing the scope trajectory (A; Modified from Longatti et al: J Neurosurg 109:530-535, 2008). When the tip of the scope reaches the position shown by the red line, the region of the inferior rhomboid fossa is clearly visible with white light (B and $E$ ). The fluorescent AP stands out when the fluorescence mode is used, appearing as 2 symmetrical, short, and thick leaves in normal cases (C and F). The position of $A P$ is seen in relation to nearby anatomical landmarks ( $D$ and $\mathbf{G})$. Copyright Alberto Feletti. Published with permission. Figure is available in color online only. 

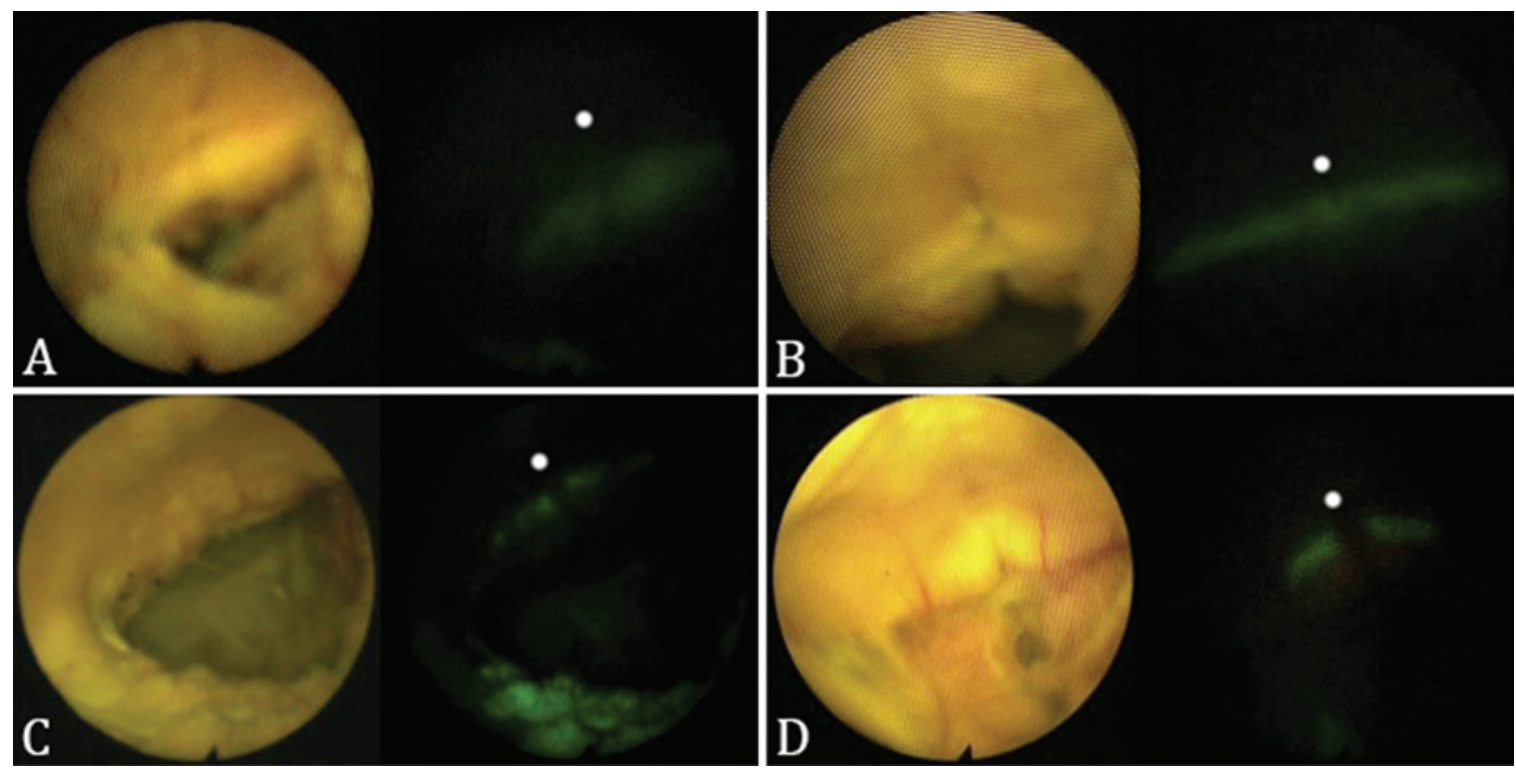

FIG. 3. Examples of anatomical variations of the AP with white light (left side of panels) and fluorescence (right side of panels). A: Short and thin leaves. B: Long, thin, and continuous leaves. C: Thin and dashed leaves. D: Separated leaves. The white dot is placed as a reference in correspondence to the canalis centralis medullaris. Figure is available in color online only.

the human rhomboid fossa using an intravascular injection of India ink and plastic fluid (Mercox), elegantly showing the position of the AP with its spongy feature and crowded vascularity, clearly distinct from surrounding structures. ${ }^{3}$ The AP has the appearance of arched wings opened on

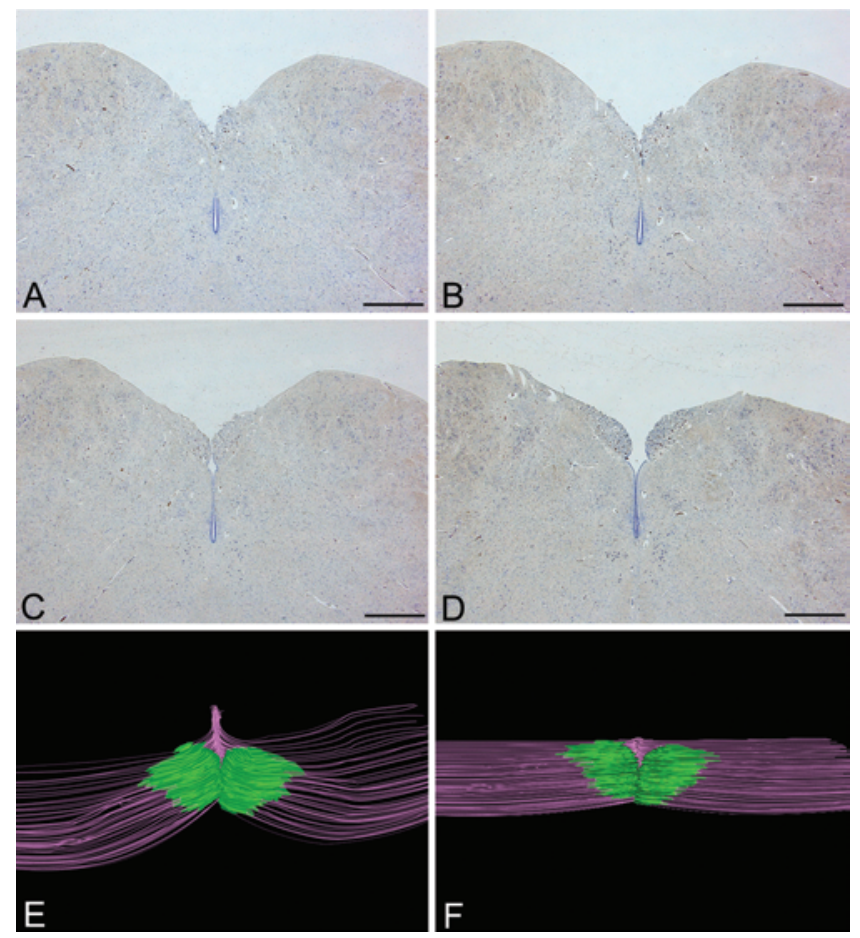

FIG. 4. A-D: Transverse sections of the medulla oblongata in caudocranial progression, showing the morphological changes of the area postrema (Nissl staining). In the most caudal levels the 2 leaves of the AP are joined together in the midline. Bars $=1.2 \mathrm{~mm}$. $\mathbf{E}$ and $\mathrm{F}$ : Posterosuperior $(\mathrm{E})$ and posterior $(\mathrm{F}) 3 \mathrm{D}$ reconstructions of the AP obtained processing every other section. Figure is available in color online only. either side of the floor of the fourth ventricle, facing the Magendie foramen and diverging from the central canal upward. The AP seems medially to cover the hypoglossal nucleus and the vagal trigone and laterally to extend far over the nucleus of the solitary tract. ${ }^{32}$ According to the classic nomenclature, the AP is delimited cranially by the funiculus separans, which separates it from the ala cinerea (dorsal motor vagal nerve), and caudally by the clava, which is technically outside the fourth ventricle. However, it is not easy to precisely detect the exact position of the $\mathrm{AP}$ in vivo. Some evidence for the identification of this organ in living subjects was reported in patients who underwent pre- and postcontrast $(5 \mathrm{ml}$ of Gadovist [gadobutrol, $1 \mathrm{mmol} / \mathrm{ml}]$ ) 3T MRI examination performed to assess the presence of pituitary microadenomas. ${ }^{6}$

During microneurosurgical procedures, the AP is rarely seen because it is mostly hidden in the calamus scriptorius and is covered by the obex. Consequently, direct and unquestionable surgical recognition of the AP in the rhomboid fossa within the complex framework of landmarks and structures contained therein has not been previously reported. Conversely, during transaqueductal neuroendoscopic navigation, the calamus scriptorius can be approached from the top downward, similar to a quill pen that is directed into the inkwell., ${ }^{912}$ For this reason, neuroendoscopy allows a clear and close visualization of the AP and central medullary canal, achieving a better definition of the position of the solitary tract nucleus, which lies below the AP, with clear advantages in terms of safety of the surgical procedure in the fourth ventricle.

This newly reported observation was possible because the AP lacks a BBB. Fluorescein is normally prevented from crossing a competent $\mathrm{BBB}$. When the BBB is damaged or absent as in the circumventricular organs, fluorescein freely flows in the interstitial space highlighting the AP. Because of these properties, fluorescein has become not only the standard agent for the study of a dam- 
aged BBB in laboratory animals, but is also an invaluable tool for ophthalmologists, who extensively use it during retinal fluorescence angiography. $7,26,27$ We have previously reported that fluorescein combined with ventricular endoscopy allows visualization of the most important circumventricular organs, in particular the median eminence and the organum vasculosum of the lamina terminalis. ${ }^{10}$ Navigation of the fourth ventricle with flexible endoscopes after fluorescein administration showed fluorescence staining of a well-defined area at the inferior extremity of the floor of the fourth ventricle, corresponding to the AP. The images obtained after fluorescein angiography and those obtained from 3D reconstructions have a definition that is comparable to that seen in Duvernoy and Risold's postmortem specimens. ${ }^{3}$ Two of our patients with a normal fourth ventricle had features that were typical of the normal AP, based on descriptions in previously reported anatomical studies. In these 2 cases the fluorescent AP had the shape of 2 short and thick diverging leaves that were cranially separated and touched each other at the midline immediately caudal to the opening of the medullary central canal. Although there are no other methods to intraoperatively confirm our observations, at least 2 findings make us confident enough to assert that what we observed is indeed the AP. First, the shape outlined by fluorescence perfectly matches the previously published histological observations of the AP. Moreover, the morphological correspondence with the $3 \mathrm{D}$ reconstruction of the AP from microscopic sections confirmed that the structure stained with fluorescein was the AP itself and offered a paradigm of the normal anatomical appearance of the AP. Thus, the endoscopic use of fluorescein may provide an important clue for the study of the microsurgical anatomy of the inferior triangle of the fourth ventricle.

Wilson reported a clear anatomical variability in the human AP. ${ }^{33}$ In some cases the 2 wings of the AP merge to form the roof of the central canal, while in others they do not join. Despite the small number of cases, we confirmed the anatomical variability of the AP, not only referring to the eventual junction between the 2 leaves, but also in terms of their shape and size. The observation that the AP can sometimes become lengthened, thin, and eventually uneven is particularly interesting. As Wilson hypothesized more than a century ago, it seems that the AP tends to adapt to the Magendie foramen morphology, especially in cases in which an enlargement of the fourth ventricle outlet is present. ${ }^{33}$ We hypothesize that the change in the AP anatomy could be due not only to a mechanical stress (for example, hydrocephalus stretches the ventricular walls and therefore tends to separate the two leaves of the AP), but also to an adaptation in order to have a more functional surface and consequently better reciprocal receptorial functions between CNS, blood, and CSF. Further endoscopic and microscopic analyses of the AP anatomy should better consider the matter of variability in the anatomy of the AP.

It is difficult to foresee the practical value of these observations. Although Lindstrom and Brizzee reported 5 cases of surgical lesioning of the AP with resolution of intractable vomiting, the use of the AP as a target for functional neurosurgical procedures is currently only hypothetical. ${ }^{8}$ However, the AP is a complex structure that regulates not only the vomiting reflex but also a number of other important functions. For this reason, we expect the AP to gain functional neurosurgical interest in the future. Although none of the patients in our series underwent surgery for tumor removal, a potential value of a clear visualization of the AP would be to avoid damage during surgery for fourth ventricle tumors. Tumors arising from the fourth ventricular floor, as ependymomas do, may be challenging. In such cases, fluorescence could help the surgeon to accurately outline and preserve the AP, and consequently to identify the layer of the ependymal surface. The AP is a firm structure for the surgeon trying to orientate him- or herself in the puzzle of the complex and only apparently similarly colored structures of the rhomboid fossa. In microneurosurgery, standard visual morphology rarely helps in identifying the anatomy of the fourth ventricle, which can hardly be determined without the valuable help of neuromonitoring. Our neuroendoscopic experience can be translated to microneurosurgery just by adding the proper filter and a blue light source to the microscope, providing a valuable landmark during surgery of the fourth ventricle. Further observations using fluorescence with the surgical microscope could better clarify the potential relationship between the morphological variations of the AP and its pathological features and functional properties.

\section{Conclusions}

Fluorescence-enhanced inspection of the fourth ventricle accurately identifies the position of the AP, which is an important landmark during surgical procedures on the brainstem. Despite the limited number of cases in this report, evidence indicates that the normal anatomical appearance of the AP is that of 2 short and thick leaves that are joined at the midline. However, there can be great variability in terms of the structure's shape and size.

\section{References}

1. Benarroch EE: Circumventricular organs: receptive and homeostatic functions and clinical implications. Neurology 77:1198-1204, 2011

2. Borison HL, Wang SC: Functional localization of central coordinating mechanism for emesis in cat. J Neurophysiol 12:305-313, 1949

3. Duvernoy HM, Risold PY: The circumventricular organs: an atlas of comparative anatomy and vascularization. Brain Res Brain Res Rev 56:119-147, 2007

4. Fry M, Ferguson AV: Ghrelin modulates electrical activity of area postrema neurons. Am J Physiol Regul Integr Comp Physiol 296:R485-R492, 2009

5. Fry M, Hoyda TD, Ferguson AV: Making sense of it: roles of the sensory circumventricular organs in feeding and regulation of energy homeostasis. Exp Biol Med (Maywood) 232:14-26, 2007

6. Horsburgh A, Massoud TF: The circumventricular organs of the brain: conspicuity on clinical 3T MRI and a review of functional anatomy. Surg Radiol Anat 35:343-349, 2013

7. Kozler P, Pokorný J: Altered blood-brain barrier permeability and its effect on the distribution of Evans blue and sodium fluorescein in the rat brain applied by intracarotid injection. Physiol Res 52:607-614, 2003

8. Lindstrom PA, Brizzee KR: Relief of intractable vomiting from surgical lesions in the area postrema. J Neurosurg 19:228-236, 1962 
9. Longatti P, Basaldella L, Feletti A, Fiorindi A, Billeci D: Endoscopic navigation of the fourth ventricle. Technical note and preliminary experience. Neurosurg Focus 19(6):E12, 2005

10. Longatti P, Basaldella L, Sammartino F, Boaro A, Fiorindi A: Fluorescein-enhanced characterization of additional anatomical landmarks in cerebral ventricular endoscopy. Neurosurgery 72:855-860, 2013

11. Longatti P, Fiorindi A, Feletti A, Baratto V: Endoscopic opening of the foramen of magendie using transaqueductal navigation for membrane obstruction of the fourth ventricle outlets. Technical note. J Neurosurg 105:924-927, 2006

12. Longatti P, Fiorindi A, Feletti A, D’Avella D, Martinuzzi A: Endoscopic anatomy of the fourth ventricle. J Neurosurg 109:530-535, 2008

13. Longatti P, Fiorindi A, Martinuzzi A, Feletti A: Primary obstruction of the fourth ventricle outlets: neuroendoscopic approach and anatomic description. Neurosurgery 65:10781086, 2009

14. Longatti PL, Martinuzzi A, Fiorindi A, Maistrello L, Carteri A: Neuroendoscopic management of intraventricular hemorrhage. Stroke 35:e35-e38, 2004

15. Macchi V, Porzionato A, Belloni AS, Stecco C, Parenti A, De Caro R: Immunohistochemical mapping of adrenomedullin in the human medulla oblongata. Peptides 27:1397-1404, 2006

16. McKinley MJ, McAllen RM, Davern P, Giles ME, Penschow J, Sunn N, et al: The sensory circumventricular organs of the mammalian brain. Adv Anat Embryol Cell Biol 172:IIIXII, 1-122, back cover, 2003

17. Miller AD, Leslie RA: The area postrema and vomiting. Front Neuroendocrinol 15:301-320, 1994

18. Mori F, Pérez-Torres S, De Caro R, Porzionato A, Macchi $\mathrm{V}$, Beleta J, et al: The human area postrema and other nuclei related to the emetic reflex express cAMP phosphodiesterases 4B and 4D. J Chem Neuroanat 40:36-42, 2010

19. Mortazavi MM, Tubbs RS, Harmon D, Oakes WJ: Chronic emesis due to compression of the area postrema by the posterior inferior cerebellar artery: resolution following microvascular decompression. J Neurosurg Pediatr 6:583-585, 2010

20. Pangestiningsih TW, Hendrickson A, Sigit K, Sajuthi D, Nurhidayat, Bowden DM: Development of the area postrema: an immunohistochemical study in the macaque. Brain Res 1280:23-32, 2009

21. Paxinos G, Huang XF: Atlas of the Human Brainstem. San Diego: Academic Press, 1995

22. Porzionato A, Macchi V, Morsut L, Parenti A, De Caro R: Microvascular patterns in human medullary tegmentum at the level of the area postrema. J Anat 206:405-410, 2005

23. Porzionato A, Macchi V, Parenti A, De Caro R: The distribution of mast cells in the human area postrema. J Anat 204:141-147, 2004

24. Potes CS, Turek VF, Cole RL, Vu C, Roland BL, Roth JD, et al: Noradrenergic neurons of the area postrema mediate amylin's hypophagic action. Am J Physiol Regul Integr Comp Physiol 299:R623-R631, 2010

25. Retzius G: Das Menschenhirn. Studien in der makroskopischen Morphologie. Stockholm: Norstedt, 1896

26. Sarmento A, Borges N, Lima D: Influence of electrical stimulation of locus coeruleus on the rat blood-brain barrier permeability to sodium fluorescein. Acta Neurochir (Wien) 127:215-219, 1994

27. Shaik IH, Miah MK, Bickel U, Mehvar R: Effects of shortterm portacaval anastomosis on the peripheral and brain disposition of the blood-brain barrier permeability marker sodium fluorescein in rats. Brain Res 1531:84-93, 2013
28. Shinpo K, Hirai Y, Maezawa H, Totsuka Y, Funahashi M: The role of area postrema neurons expressing H-channels in the induction mechanism of nausea and vomiting. Physiol Behav 107:98-103, 2012

29. Sisó S, Jeffrey M, González L: Sensory circumventricular organs in health and disease. Acta Neuropathol 120:689-705, 2010

30. Stein MK, Loewy AD: Area postrema projects to FoxP2 neurons of the pre-locus coeruleus and parabrachial nuclei: brainstem sites implicated in sodium appetite regulation. Brain Res 1359:116-127, 2010

31. Tork I, McRitchie DA, Rikard-Bell GC, Paxinos G: Autonomic regulatory centers in the medulla oblongata, in Paxinos G (ed): The Human Nervous System. New York: Academic Press, 1990, pp 221-259

32. Wang QP, Guan JL, Pan W, Kastin AJ, Shioda S: A diffusion barrier between the area postrema and nucleus tractus solitarius. Neurochem Res 33:2035-2043, 2008

33. Wilson JT: On the anatomy of the calamus region in the human bulb; with an account of a hitherto undescribed "nucleus postremus.”: Part I. J Anat Physiol 40:210-241, 1906

34. Wuerfel E, Infante-Duarte C, Glumm R, Wuerfel JT: Gadofluorine M-enhanced MRI shows involvement of circumventricular organs in neuroinflammation. J Neuroinflammation $7: 70,2010$

\section{Author Contributions}

Conception and design: Longatti. Acquisition of data: Feletti, Basaldella, Fiorindi, De Caro. Analysis and interpretation of data: Feletti, Longatti, Porzionato. Drafting the article: Feletti, Longatti, Porzionato. Critically revising the article: Feletti, Longatti, Porzionato, Basaldella, Fiorindi. Reviewed submitted version of manuscript: all authors. Approved the final version of the manuscript on behalf of all authors: Feletti. Study supervision: Longatti.

\section{Supplemental Information}

\section{Previous Presentation}

Portions of this work were presented in poster form at the 82nd AANS 2014 Annual Scientific Meeting, San Francisco, California, April 5-9, 2014.

\section{Videos}

Video 1, Media Player. http://mfile.akamai.com/21490/wmv/ digitalwbc.download.akamai.com/21492/wm.digitalsource-naregional/jns14-482_video_1.asx.

Video 1, Quicktime. http://mfile.akamai.com/21488/mov/ digitalwbc.download.akamai.com/21492/qt.digitalsource-global/ jns14-482_video_1.mov.

Video 2 , Media Player. http://mfile.akamai.com/21490/wmv/ digitalwbc.download.akamai.com/21492/wm.digitalsource-naregional/jns14-482_video_2.asx.

Video 2, Quicktime. http://mfile.akamai.com/21488/mov/ digitalwbc.download.akamai.com/21492/qt.digitalsource-global/ jns14-482_video_2.mov.

\section{Correspondence}

Alberto Feletti, Department of Neurosurgery, Treviso Hospital, University of Padova, Piazza Ospedale 1, 31100 Treviso, Italy. email: alberto.feletti@gmail.com. 